ISSN 1518-3483

Licenciado sob uma Licença Creative Commons

\title{
Práticas de iniciação à docência: 0 diário de campo como instrumento para pensar a formação de professores
}

\author{
Practices of initiation to teaching: the field diary as an \\ instrument to think about the formation of teachers
}

\section{Sandra de Oliveira, Elí Henn Fabris*}

\section{Resumo}

O artigo é resultado de um recorte da pesquisa de doutorado (OLIVEIRA, 2015) defendida no início de 2015 em articulação com pesquisa desenvolvida (FABRIS, 2013-2016) em um programa de pós-graduação em Educação no Brasil. O estudo busca dar visibilidade a alguns elementos que compõe as práticas de iniciação à docência a partir do uso do diário de campo por um grupo de licenciandas em Pedagogia, vinculadas ao primeiro programa brasileiro de bolsa de iniciação à docência (Pibid). Apoiado nos campos teóricos dos Estudos em Docência e dos Estudos Foucaultianos e fazendo uso da ferramenta teórico-metodológica da subjetivação como operador analítico, o exercício recorreu a um

\footnotetext{
SO: Doutora em Educação, e-mail: sandradeoliveira.rs@gmail.com
}

EHF: Doutora em Educação, e-mail: ethfabris@gmail.com 
conjunto de materiais produzidos por meio de um questionário semiestruturado e de diários de campo produzidos pelos sujeitos pesquisados. Resultados indicam o diário de campo como um potente instrumento para a formação de professores. Por meio de uma formação alicerçada nos fios constitutivos do saber, do poder e da ética, tal instrumento torna-se uma tecnologia humana produtiva de formas específicas e contingentes de subjetividades docentes.

Palavras-chave: Diário de campo. Formação de professores. Subjetividades.

\section{Abstract}

The article is the result of a segment of the doctoral research (OLIVEIRA, 2015) defended in early 2015 in join with a research (FABRIS, 2013-2016) carried out in a postgraduate program in Education in Brazil. The study seeks to show some elements that comprise the practices of initiation to teaching based on the use of a field diary by a group of Pedagogy licensed linked to the first Brazilian program of initiation to teaching (Pibid). The exercise was made up of a set of materials, produced through a semistructured questionnaire, in addition to the field diaries written by the subjects under analysis, supported in the theoretical fields of both Studies in Teaching and Foucaultian Studies, as well as making use of the theoretical-methodological tool of subjectivity as an analytical operator. The results indicate that the field diary is a powerful tool for the teacher training. By means of a formation, based on the threads of knowledge, power, and ethics, such instrument becomes a productive human technology of specific and contingent forms of teaching subjectivities.

Keywords: Field diary. Teacher training. Subjectivities. 


\section{Introdução}

Neste artigo apresentamos um recorte da pesquisa de doutorado (OLIVEIRA, 2015) defendida no início de 2015 em articulação com pesquisa em desenvolvimento (FABRIS, 2013-2016) em um programa de pós-graduação em Educação no Brasil. Nesse recorte, buscou-se dar visibilidade a alguns elementos que compõe as práticas de iniciação à docência a partir do uso do diário de campo por um grupo de licenciandas em Pedagogia vinculadas ao primeiro programa brasileiro de bolsa de iniciação à docência (Pibid). No decorrer do exercício analítico, argumentamos que esses elementos estão a indicar certa potência para a realização de um trabalho ético voltado para a constituição das subjetividades docentes contemporâneas.

Apoiadas nos campos teóricos dos Estudos em Docência e dos Estudos Foucaultianos, analisamos a formação inicial desenvolvida por esse Programa de Iniciação à Docência, considerado uma das ações de maior relevância e impacto no âmbito da formação de professores no Brasil nas últimas décadas. O Programa visa promover a inserção dos estudantes de licenciatura no contexto das escolas públicas desde o início da sua formação acadêmica para que desenvolvam práticas de iniciação à docência sob a orientação de um(a) professor(a) universitário(a) e de um(a) professor(a) da educação básica. Tais práticas estão alicerçadas na relação universidade e escola e na busca da superação da dicotomia teoria e prática.

Fazendo uso da ferramenta teórico-metodológica da subjetivação como operador analítico, o exercício recorreu a um conjunto de documentos produzidos pelos sujeitos participantes do programa Pibid em um curso de Licenciatura em Pedagogia de universidade da região Sul do Brasil (2012-2014) por meio de um questionário semi-estruturado criado a partir da ferramenta Google Form ${ }^{1}$. Também fizeram

1 Google Drive é um serviço que disponibiliza ferramentas virtuais gratuitas de pesquisa. A ferramenta utilizada para criação de formulário de coleta de dados da presente pesquisa foi Google Form. Disponível em: <https://drive.google.com/>. Acesso em: 12 fev. 2014. 
parte dos materiais de análise, diários de campo dos sujeitos pesquisados, materiais de reuniões do projeto, entre outros.

As práticas de iniciação à docência, tomadas aqui como tecnologias humanas (FOUCAULT, 2004), envolvem os sujeitos pibidianos em trabalho ético, no qual são levados a analisar o outro e a si mesmos, mantendo um estado de reflexão permanente sobre o ser docente e o tornar-se professor/a. Esses exercícios de análise e reflexão (de si consigo e com os outros) configuram-se em práticas de si que levam o sujeito a constituir-se, tornar-se professor/a, no interior de certos princípios e regras de conduta, fabricando determinados modos de ser e de agir enquanto docente.

\section{O diário de campo: observação e escrita como elementos da constituição de si mesmo}

As práticas de iniciação à docência identificadas no PibidPedagogia propõem uma ética e uma ascética para os pibidianos ${ }^{2}$, interpelam os sujeitos em seu processo de formação com determinados discursos e exercícios que conformam aquilo que Michel Foucault (1994a) denominou de técnicas de si. Essas práticas nas quais se estabelecem, se regulam e se modificam as relações do sujeito consigo mesmo, essas práticas enquanto tecnologias, são elas mesmas, mecanismos de produção da experiência de si.

As práticas que envolvem uma dimensão ética se relacionam intimamente com as práticas de saber e de poder, imprimindo no sujeito determinados modos de ser, num processo que é histórico e cultural. É nessa complexidade que se constitui o sujeito e é para esse emaranhado de fios constitutivos que precisamos olhar para analisar

\footnotetext{
2 Adotamos o uso pibidiano, no masculino, por ser esta a forma recorrente encontrada no âmbito do Programa, mesmo entre as alunas da licenciatura em Pedagogia do projeto analisado, prevalece a expressão "Sou Pibidiano!".
} 
seus modos de ser. Sobre isso, Nietzsche (1983) nos diz que somos produtos de uma tradição, mas que é possível, através de certos processos, um transformar-se, com outros conhecimentos, com outros saberes, atingindo novas formas de vida, de ser e estar no mundo.

Nessa proposta de formação, as relações estabelecidas tornam-se fundamentais, visto que a transformação não se dá na ordem da "introspecção, mas na ordem dos agenciamentos: tornamo-nos quem somos não por manifestar uma essência dada desde sempre, mas pelo encontro com a alteridade, pela forma como assimilamos as experiências, como assimilamos a diferença, como nos transformamos no embate com as circunstâncias" (ROCHA, 2009, p. 50).

Tornar-se professor/a, nesse sentido, implica incorporar certos modos de ser e de agir considerados próprios de um sujeito docente em uma determinada cultura. Esses modos de ser e agir são apreendidos por intermédio de exercícios, técnicas e rituais facilmente identificados no âmbito do Programa Pibid. A ênfase no exame de tais materiais e suas formulações discursivas foi mostrar como eles estão envolvidos na produção de figuras modelares da docência.

Ao realizar a análise do material foi possível identificar o uso do diário de campo nas práticas de iniciação à docência do PibidPedagogia em pelo menos cinco ações: a observação, a escrita, a análise (ou reflexão), a leitura ou exposição, o aconselhamento. A seguir procuramos mostrar o quanto essas ações foram incorporadas aos rituais pibidianos, configurando práticas de ascese e operando na condução da conduta dos/as futuros/as professores/as.

As licenciandas escrevem sobre si, evocam memórias das práticas de iniciação à docência realizadas por elas ou observadas, mencionam situações vividas como alunas da educação básica e outras que vivenciaram no curso de formação inicial. As conexões realizadas e organizadas por meio da escrita e da evocação da memória produzem subjetividades. Todo esse conjunto de observações que resultam de um exercício de vigilância e inspeção do outro e de si mesmo, amarrados à trama de discursos verdadeiros sobre a docência que atravessam as 
práticas de iniciação à docência, tornam possíveis os processos de subjetivação acionados pela escrita de si.

O exercício de escrita identificado no projeto Pibid-Pedagogia analisado nesse artigo evidencia a unificação de discursos verdadeiros num só corpo, um corpo que se assujeitou. É pela subjetivação, através da escrita de si, que esses discursos se tornam corpo, se tornam sujeito. O vínculo criado entre os participantes do projeto a partir do ethos de formação (DAL'IGNA; FABRIS, 2013), que os convoca a uma unidade, que os liga em comunidade, esse vínculo cria a possibilidade do estabelecimento de relações de cumplicidade que repercutem em uma maior exposição de suas escritas, das reflexões realizadas, dos exercícios de pensamento. Os rituais pibidianos possibilitam que essa discursividade possa ser reelaborada, construída como elemento importante da constituição de si mesmo. Escrever sobre si e para o outro implica no acionamento de uma série de princípios que operam na eticalização de si e tornam possível a elaboração de elementos da dimensão ética como conformadores de suas subjetividades. Observemos os excertos:

Minha atitude na escola é de observação e aprendizado, tento ao máximo aprender, mas com uma atitude crítica, pois não quero de modo nenhum "reproduzir" práticas que não considero didáticas e que não fazem sentido para o aluno.

Fonte: Banco de Dados da Pesquisa: Formulário- Bolsista 6 Pibid-Pedagogia.

Antes de ser pibidiana acreditava que "dar aula" era uma coisa natural, fácil, depois dessa experiência percebi que há a necessidade de observação, planejamento e responsabilidade na prática docente. Tornei-me mais observadora, questionadora tanto na escola quanto na academia, nas práticas docentes observadas nesses dois espaços. Aprendi a refletir sobre minhas práticas e como e por que utilizar esse ou aquele material ou conteúdo. Passei a dar um valor de responsabilidade social a Educação e a prática docente que acredito que somente o curso de Pedagogia não conseguiria impregnar na minha formação.

Fonte: Banco de Dados da Pesquisa: Formulário- Bolsista 2 Pibid -Pedagogia. 
Passei por duas escolas, quatro supervisoras, quase uma dezena de colegas bolsistas, muitas vivências e experiências, positivas e negativas com relação ao Programa. Mas como já citei, a principal característica que desenvolvi com a experiência foi saber observar e como fazer uso dessa aprendizagem, tanto na prática docente quanto na minha formação.

Fonte: Banco de Dados da Pesquisa: Formulário - Bolsista 2 Pibid- Pedagogia.

Um dos primeiros exercícios propostos ao pibidiano é a observação. Uma vez incorporada pela licencianda, a observação passa a permear todas as demais vivências que ela realiza na escola (e também na universidade). Ao observar o/a professor/a no exercício de sua docência, no âmbito da escola, o pibidiano é orientado a realizar análise dessas práticas, incentivado a refletir sobre elas, fazer registros em seu diário de campo, narrar suas percepções, dúvidas, inquietações frente ao observado, em diferentes momentos e atividades propostas pelo Pibid-Pedagogia.

As narrativas encontradas em registros das licenciandas explicitam o teor reflexivo que deve acompanhar as observações realizadas na escola, conforme orientações nas reuniões do projeto. Ocorre que, ao analisar o outro enquanto sujeito da docência, o pibidiano é levado a pensar sobre si próprio e a colocar-se no lugar do outro, uma vez que, efetivamente, tem a possibilidade de, nas práticas de iniciação à docência, em determinados tempos e espaços, assumir esse lugar, tomar um outro posicionamento, experimentando-se enquanto sujeito docente em formação. Nesse exercício de observar e julgar, observar-se e julgar-se, o sujeito tem a possibilidade de (re)construir a si próprio. Verifiquemos mais alguns excertos:

A principal característica que acrescentaria pós-PIBID é a da observação. Aprendendo essa prática fundamental é possível mudar nossa maneira de planejar e aplicar conteúdos. Dentro da minha experiência de pibidiana aprendi ainda que a educação vai além da sala de aula e que a responsabilidade social é parte integrante do docente e que pequenos gestos transformam vidas e é imensamente gratificante. Aprendi que todos podem aprender, 
sejam alunos, pais, professores, basta dedicar-se e encarar cada dia como uma nova oportunidade de fazer mais e melhor. Posso dizer que ao longo da minha formação somada a experiência do PIBID percebi que o sonho utópico da Educação não acontece em larga escala, mas em pequenos movimentos diários e feitos com responsabilidade.

Fonte: Banco de Dados da Pesquisa: Formulário - Bolsista 2 Pibid- Pedagogia.

O Pibid faz com que nós, alunos da Graduação, possamos vivenciar a prática docente, em muitos sentidos: observação das turmas de alfabetização, registro em diário de campo, diagnóstico de problemas enfrentamos pela professora e alunos, planejamento e intervenções coletivas e/ou individuais. E o mais interessante, não é nossa a responsabilidade em alfabetizar as crianças. A formação como pibidiana se fez essencial, pois estava vivenciando problemas enfrentados na alfabetização antes de atuar como professora e ter a responsabilidade de alfabetizar os alunos. Isso é sem dúvida, produtivo, pois antes de ser formada já podia observar, atuar e refletir sobre os problemas que perpassam a alfabetização hoje. Também os encontros de formação mensais se fazem muito produtivos, pois temos a Universidade refletindo conosco, sobre aquilo que vivencia-se na escola.

Fonte: Banco de Dados da Pesquisa: Formulário - Bolsista 5 Pibid-Pedagogia.

Ao analisar aquilo que está sendo observado, o pibidiano toma como referência determinados parâmetros previamente estruturados sobre a docência, ou ainda, sobre uma ideia de docência, histórica e culturalmente constituída. Sua análise das práticas observadas está permeada por discursos incorporados como verdadeiros a respeito do que é ser "bom/boa professor/a" e do que são "boas práticas" pedagógicas, que acabam por compor modelos. Seu olhar, ao observar, está direcionado por esses modelos que, uma vez estabelecidos dentro do que é aceitável e do que não é aceitável, segundo padrões de classificação, servem como referência para a análise e constituição das práticas docentes para os anos iniciais da educação básica. Isso não está separado das teorias psicológicas da aprendizagem, do desenvolvimento infantil, da alfabetização, das competências e habilidades tidas 
como próprias da docência contemporânea, entre outras discursividades que conformam os saberes docentes no âmbito do curso de licenciatura em Pedagogia e das políticas de formação inicial de professores no Brasil, incluído aí o Programa Pibid.

Esse exercício de observar, registrar e analisar está atravessado por um conjunto de verdades discursivas e não discursivas que tornam possível ver certas coisas e não outras, ver de uma forma e não de outra, "com toda a organização espaço-temporal que implica, estabelece, em um só movimento, o sujeito e o objeto da visão" (LARROSA, 1994, p. 25).

Ao observar a prática docente no espaço da escola, o pibidiano identifica-se com uma, busca diferenciar-se de outra e passa a discernir aqueles modos de ser professor/a que deseja incorporar em suas práticas e aqueles que não deseja. Essas escolhas estão ligadas aos discursos políticos e científicos, às normas da profissão, a padrões e códigos institucionais, enfim às ordens explicativas "vigentes" acerca da docência.

Os pibidianos, em meio às práticas de iniciação à docência, não são simplesmente indivíduos que tem experiências em contato com as escolas. Conforme Garcia, Fonseca e Leite (2013), ao inserirem-se no âmbito escolar, "os licenciandos são constituídos no interior dessas experiências que são fundamentalmente discursivas, sendo, portanto, também atravessados pela rotina, pela burocracia, pela tradição, pelo conservadorismo, etc." (GARCIA; FONSECA; LEITE, 2013, p. 260).

O processo de constituição de si, de subjetivação, embora num primeiro momento pareça individual, se dá no âmbito das relações. É na relação com o outro e no encontro com as diferenças desse outro, numa espécie de embate, de jogo de tensões que esse encontro proporciona, que se potencializam as possibilidades de transformação de si mesmo. É a partir dessas relações do sujeito consigo mesmo e com os outros, dessa relação consigo e dos agenciamentos produzidos por múltiplas relações, que as licenciandas acabam por se tornar docentes de um determinado tipo. Tais agenciamentos, que se dão no âmbito das práticas, por um lado, possibilitam aos pibidianos reconhecer-se como sujeitos da docência, por outro, também estão a 
produzir sujeitos capazes de relacionar-se consigo mesmos, regulando suas condutas, governando a si e aos outros.

Podemos observar essas tensões, identificações, diferenciações que se estabelecem no campo das relações a partir das observações realizadas pelos pibidianos em reflexões registradas nos seus diários de campo: "A preocupação em atender as especificidades dos alunos é algo a ser destacado", "tudo o que for desenvolvido com meus alunos terá de ser significativo", "Vejo-me como uma professora que se preocupa com o aluno, e que leva em conta seu contexto e suas vivências", "As práticas que interdito são aquelas que não levam em consideração o aluno, mas simplesmente o conteúdo que deve ser 'passado"', "por usá-la de forma que fazia sentido para as crianças, caracterizo seu trabalho como inovador". Os registros acima retirados de diários de campo das licenciandas não são apenas anotações; eles são a materialidade dos discursos verdadeiros que ganham caráter de legitimidade ao serem observados no fazer docente e vão sendo incorporados pelos pibidianos por meio de diferentes exercícios. Um dos exercícios mais potentes no processo de subjetivação, de constituição de si é, pois, a escrita.

Conforme Foucault (1994a, p. 8), "[...] o ato de escrever intensifica e aprofunda a experiência de si. Todo um campo de experiências que não existia anteriormente se abre". "Escrever é, portanto, 'se mostrar', se expor, fazer aparecer seu próprio rosto perto do outro” (FOUCAULT, 2010b, p. 156). A escrita, como exercício, opera, ao mesmo tempo, nos dois processos de constituição do sujeito: de objetivação e de subjetivação. Ao dividir-se aquilo que escreve com o outro, essa reciprocidade estabelecida, "não é simplesmente do conselho e da ajuda, ela é do olhar e do exame [...] trabalha para a subjetivação do discurso verdadeiro, para sua assimilação e elaboração como 'bem próprio', constitui também e ao mesmo tempo, uma objetivação da alma" (FOUCAULT, 2010b, p. 156).

Quando o pibidiano escreve sobre o que observou, vivenciou ou realizou nas práticas de iniciação à docência, aciona um sistema prescritivo moral, transformando a si em sujeito moral de sua conduta, conforme certa normatividade dos comportamentos docentes. Apenas para ilustrar, citamos alguns comportamentos, ou ainda, alguns modos de ser e agir que 
foram identificados nos registros das licenciandas como legítimos e importantes: observador/a, reflexivo/a comprometido/a, flexível, inovador/a, responsável, preocupado/a, amoroso/a, atualizado/a, entre outros.

É possível afirmar no âmbito do projeto Pibid-Pedagogia analisado e a partir do tema foucaultiano da escrita de si, a existência de um importante material para a análise e compreensão do que a formação inicial de professores tem produzido enquanto docência contemporânea; em outras palavras, o que os sujeitos pibidianos estão fazendo consigo mesmos e de que maneira, a partir disso, estão constituindo modos de ser e agir enquanto docentes dos anos iniciais da educação básica?

É no diário de campo que as licenciandas realizam registros das observações e práticas, das reflexões a partir do observado ou vivenciado, do planejamento, das conversas ou reflexões realizadas com a supervisor/a, colegas ou coordenador/a, das anotações de reuniões, de atividades de formação ou para os relatórios, das narrativas, dos artigos com resultados de práticas ou relatos de experiências, dos sentimentos, desejos, tensões, inquietações, de conhecimentos adquiridos, metodologias criadas, situações vivenciadas com professores/as, com alunos/as, conflitos e soluções encontradas; enfim, o diário de campo do pibidiano deve refletir o cotidiano das práticas de iniciação à docência.

Para Lewgoy e Arruda (2004, p. 123-124), o registro no diário de campo é "um exercício acadêmico na busca por uma identidade profissional". A ferramenta diário de campo participa da produção de um/a professor/a observador/a, registrador/a, reflexivo/a, com postura investigativa. A proposta não é de uso apenas durante o projeto Pibid, mas de que o/a futuro/a docente possa tornar essa ferramenta parte de seu material de trabalho, tornar a prática de registro no diário de campo parte de sua jornada profissional, de seu fazer enquanto sujeito da docência. O diário de campo é organizado cronologicamente, de modo que o pibidiano possa observar registros antigos, retomar, refletir, comparar.

O diário de campo também se mostrou eficaz no sentido que apontaram algumas bolsistas que manifestaram certa insegurança em analisar de modo crítico o trabalho dos/as professores/as da escola em que estavam 
inseridas. No início das observações realizadas, as licenciandas pouco conversavam com o/a professor/a observado/a sobre suas práticas. Citaram o diário de campo como espaço possível para registrar suas tensões, contradições, discordâncias, dúvidas, inquietações frente ao observado.

É possível identificar, na descrição das reuniões realizadas com a coordenadora do subprojeto Pibid-Pedagogia, alguns elementos comuns às reuniões chamadas de pedagógicas ou da tradição escolar. A presença do diário de campo, contudo, e os usos que vêm sendo feito dele, nos possibilitam analisar as práticas de iniciação à docência a partir da problematização da dimensão ética na formação inicial de professores.

\section{Rituais pibidianos: a leitura pública do diário de campo}

Segundo Foucault (2004, p. 213), "Há também diferentes possibilidades nas formas de 'elaboração' do trabalho ético realizado sobre si mesmo, não apenas para tornar seu comportamento conforme uma regra dada, mas sim para tentar transformar a si mesmo em sujeito moral de sua conduta". A escrita, a leitura e a escuta são técnicas de si importantes para a ascese, para a elaboração desse trabalho ético. $\mathrm{Na}$ esteira desses pensamentos, podemos compreender as reuniões ritualizadas do Pibid-Pedagogia como parte de um trabalho ético, como espaços potencializadores das técnicas de si.

Na descrição das reuniões, foi possível observar a presença do diário de campo como um importante instrumento utilizado nos rituais pibidianos. A proposta do uso do diário de campo no subprojeto Pibid-Pedagogia é individual, e cada pibidiano deve ter o seu caderno para realizar as escritas referentes às práticas de iniciação à docência. Contudo, o seu conteúdo pode ser partilhado com os/as colegas, com o/a professor/a supervisor/a entre outros/as integrantes do Pibid. Uma das maneiras em que ocorre essa partilha é quando realizam leituras de suas escritas nas reuniões que ocorrem na escola ou na universidade. As bolsistas são incentivadas a levar seus diários e ler suas narrativas, suas impressões e reflexões em voz alta para os/as colegas. Ao ser partilhado em leitura oral nas reuniões, o diário de campo recebe 
também um caráter de publicidade e coletividade, pois todos/as são convidados/as a participar da problematização, com o objetivo de superar análises de senso comum que muitas vezes permeiam os registros. Observemos diferentes usos nas falas das bolsistas:

Procuro realizar o diário de campo na própria escola sempre após o recreio, até pelo fato de não acabar me esquecendo das rotinas e práticas vivenciadas em salas de aula (atuo em uma turma de $3^{\circ}$ e $4^{\circ}$ ano). Em relação à escrita, uso em $1^{\mathrm{a}}$ pessoa. Como somos nós, pibidianos, que devemos escrever sobre todas as coisas que achamos importantes, creio que em $1^{\mathrm{a}}$ pessoa fica uma forma mais fácil de entender o que relatamos no diário de campo. Com certeza realizo reflexão e análise de cada aula observada ou de interação (quando sou eu que aplico a aula). Não mostro para ninguém o diário. A professora supervisora nos respeita em relação a isso. É de uso pessoal. Procuramos ler o que escrevemos, mas, sempre há discussão e debate sobre o que vivenciamos em salas de aula (pode ser alguns tópicos do que relatamos no diário). Sim, e muito. Procuro sempre fazer análises e opinar a respeito das observações feitas nas turmas. Isso é um material enriquecedor para os docentes. Às vezes são coisas boas e às vezes não, infelizmente. Creio que é uma forma de poder buscar soluções ou, até mesmo, respostas para perguntas e problemas frequentes. Ao escrever no diário de campo estou realizando algo importante, porque sempre que surgir algo parecido com o que já houve, busca-se nesse material para daí encontrar algo como solução e tentar inverter as coisas. O que julgo importante é ter tido uma oportunidade como essa de ter onde escrever/relatar sobre nossas/minhas vivências em uma escola, em uma sala de aula.

Fonte: Banco de Dados da Pesquisa: Formulário - Bolsista 8 Pibid- Pedagogia.

Acredito que ter este material (o diário) e poder discuti-lo com outros pibidianos é algo muito produtivo, pois as informações vêm de situações reais, que aconteceram "hoje" na escola. Então, na Universidade, com meus colegas, também podia discutir sobre aquilo que estava, de fato, acontecendo. Penso que o Pibid poderia investir mais no estudo do diário de campo, fazer grupos de discussões, com os bolsistas e com o professor Coordenador de área, tendo como base as práticas observadas, sobre aquilo que anotamos no caderno. Para que assim os pibidianos possam refletir e posicionar-se criticamente.

Fonte: Banco de Dados da Pesquisa: Entrevista - Bolsista 5 Pibid-Pedagogia. 
Nesse sentido, cabe aludir a Masschelein (2014, p. 20), a respeito do ato de tornar público um discurso, o autor defende que, quando alguém se dirige a outrem "sob a suposição de igualdade, falando em seu próprio nome", ali se instaura um "ethos para a própria pessoa se arriscar”. Quando o sujeito se “[...] expõe aos limites (da instituição, da máquina) e está transformando a questão da qual se está falando em uma questão pública, isto é, tornando-a pública”, é nessa exposição que se dá entre colegas, entre estudiosos - que se constitui "um 'público' para além de qualquer máquina ou instituição” (MASSCHELEIN, 2014, p. 20).

A escrita em um diário que se destina a ser compartilhado e lido perante um grupo, borra as fronteiras entre o privado e o público. Conforme já inferimos, esses tipos de escritas de si estão presentes nos rituais pibidianos, dando origem a conversas, trocas de opiniões, conselhos, sugestões de modos de conduta. Embora os/as colegas participem dessa conversa, o papel da professor/a supervisor/a, nesse caso, merece especial destaque, pois ele/a é aquele/a que detém os "saberes práticos" acerca da docência (a expertise sobre o que funciona e o que não funciona ao exercer-se à docência). O que ele/a diz é ouvido com especial atenção. São enunciações que, para as bolsistas, têm valor prescritivo. Essas sugestões de modos de agir perante tais situações pedagógicas oriundas das práticas de iniciação à docência, esses conselhos, exigem o olhar do sujeito sobre si mesmo. Ao serem memorizados os conselhos ouvidos e incorporados ao conjunto de matrizes de ação acerca da docência, tais discursos são subjetivados, constituindo o sujeito pibidiano. A escuta é, pois, uma das técnicas para a subjetivação do discurso verdadeiro, do logos.

Outro aspecto que foi possível identificar no material analisado é que os pibidianos consideram de suma importância a reflexão crítica sobre as práticas e denunciam colegas que não a realizam. Esse exercício de vigilância de si e do outro, de julgar-se e de julgar o outro, está sempre marcado pelas verdades que o assujeitaram, fazem parte de 
um arsenal de memória e de tradição, desses jogos de verdade sobre a docência. Observemos:

Penso que o Pibid é um ótimo Programa para os alunos que querem aprender e ter uma visão crítica, pois muitos pibidianos acabam apenas sendo um auxiliar da professora e não refletem sobre as práticas.

Fonte: Banco de Dados da Pesquisa: Entrevista - Bolsista 6 Pibid- Pedagogia.

Ao problematizar as práticas observadas, os pibidianos estabelecem interlocução com seus pares, com o/a professor/a supervisor/a, com o/a coordenador/a de área e, muitas vezes, com o/a próprio/a docente observado/a, o que parece ser possibilitado pela existência de certo vínculo e comprometimento entre os participantes do projeto. Isto pode ser percebido no excerto abaixo, retirado de uma entrevista, onde a bolsista fala sobre as possibilidades de interlocução, discutindo sobre as questões que a colocam a refletir a partir das observações realizadas:

Eu acho que começa primeiro colega a colega, a discussão disso aí, quando tem um problema começa as colegas discutindo, que nem tu falou [...], a gente conversa ali entre os pibidianos. Daí depois a gente chama a professora supervisora. É o passo que eu estou te dando, primeiro passo, entre colegas. Segundo passo, a supervisora. Terceiro passo, às vezes, a gente conversa com a professora da turma que observamos. Daí, quarto passo, a gente discute com o coordenador do Pibid-Unisinos-Pedagogia.

Fonte: Banco de Dados da Pesquisa: Entrevista- Bolsista 3 Pibid- Pedagogia.

Outro fator que possibilita o vínculo observado é o tempo de permanência das bolsistas no projeto e em consequência, na escola e nos rituais pibidianos. Esse vínculo gera diferentes possibilidades de estabelecimento de relações e é gestado a partir do ethos instaurado no projeto, o que cria um espírito de cooperação e partilha entre os pibidianos.

Segundo Sennett (2013), a relação dialógica se faz fundamental para o trabalho cooperativo. Em sua obra Juntos, o autor descreve uma 
gama de habilidades necessárias para que a cooperação seja possível, entre elas cita a capacidade de observar, o que implica em saber ouvir o outro com atenção e interpretar o que ouviu, antes de emitir análise. Ao exercitar a observação, o sujeito aprende a conter-se perante a ânsia de emitir rápido julgamento. As conversas posteriores a esses exercícios de observação, conforme Sennett (2013) vão se tornando mais ricas, mais cooperativas e dialógicas. Consideremos os trechos a seguir:

Depois de anotar tudo que via nas aulas das professoras alfabetizadoras, pegava o caderno e lia, fazendo uma primeira análise daquele material. Não anotava esta análise, apenas refletia, pensava e problematizava as práticas e discursos que eu acreditava estarem colocados ali. Às vezes mostrava o caderno para alguns colegas da Universidade, para eles poderem ver as práticas, sendo que juntos fazíamos o exercício de discuti-las e problematizá-las. Gostava de ter o material empírico para poder fazer este exercício de reflexão. Ao fazer o relatório mensal me posicionava criticamente e então, colocava as análises realizadas e minha percepção do trabalho que vinha acontecendo na escola.

Fonte: Banco de Dados da Pesquisa: Entrevista - Bolsista 5 Pibid-Pedagogia.

[...] a gente sempre pode melhorar em tudo [...], eu acho que enquanto eu estiver crescendo como pessoa, ser humano, o Pibid vai me ajudar a colocar estas reflexões todas que eu tenho, me levar para sala de aula, oportunizar essa ligação. Agora eu estou entrando na área das cadeiras específicas aqui na Unisinos e isto está sendo muito bacana, porque eu estou conseguindo levar o que eu estou aprendendo aqui para sala de aula e sem o Pibid eu não teria isso. O Pibid, às vezes, é muito ruim, tu pensa que tu tem que ir lá para escola e ficar quatro horas lá sentada observando uma aula, que tu já sabe o que acontece em sala de aula. Daí tu vai, entra dentro da sala de aula e tu percebe que tu não sabe tudo, que tem coisas para ti aprender ali, que naquele dia tu vai pontuar e vai ser diferente. Então eu acho que o Pibid oportuniza isso, deveria ser para todos, opinião minha, eu acho que todos deveriam passar por essa experiência.

Fonte: Banco de Dados da Pesquisa: Entrevista - Bolsista 2 Pibid- Pedagogia. 
O excerto acima nos mostra o quanto a observação, por si só, muitas vezes se revela como um exercício individual e entediante para as licenciandas. A prática do registro e a exploração posterior do que foi observado e registrado, contudo, pode gerar uma prática coletiva e dialógica.

A escrita, a leitura e a escuta são elementos que contribuem para a rememoração dos discursos verdadeiros, constituindo práticas de ascese, cujo propósito consiste em adquirir algo que ainda não se possui, as matrizes práticas de ação. As práticas de ascese dotam o sujeito de esquemas pragmáticos e prescritivos. O objetivo desse tipo de prática, conforme explica Foucault (2001, p. 481), é "[...] dotar o sujeito de uma verdade que ele não conhecia e que não residia nele, trata-se de fazer dessa verdade aprendida, memorizada, progressivamente aplicada, um quase-sujeito que reina soberamente em nós".

Essas prescrições sobre como conduzir-se em determinada situação são realizadas por meio de conselhos. Esses modos de aconselhamento para a ação fazem parte da subjetivação de discursos verdadeiros sobre a docência. Nos excertos a seguir, podemos verificar a presença desses conselhos na relação estabelecida entre a licencianda e a professora supervisora e o quanto eles participam da constituição dos modos de se conduzir das futuras professoras. Segundo uma delas, eles "ajudam a enxergar melhor", observemos:

Com a professora supervisora eu tenho é um acompanhamento. Se eu estou com algum problema, até na faculdade, eu ligo "(nome da professora), eu estou assim, assim", eu descrevo a situação, digo "é um aluno de quarta série e coisa e tal". Ela me passa por telefone a experiência dela, é muito interessante o quanto isso me ajuda.

Fonte: Banco de Dados da Pesquisa: Entrevista - Bolsista 3 Pibid- Pedagogia.

É [...] aprendi como me posicionar diante do aluno. Isso ela (a professora supervisora) sempre quando eu tive problemas eu ia lá e ela dizia " $n a ̃ o, ~ t u$ volta, tu faz assim, assado", ela sempre me orientava.

Fonte: Banco de Dados da Pesquisa: Entrevista - Bolsista 2 Pibid- Pedagogia. 
A professora acaba sempre me dando uma ideia. Depois eu sempre tenho mania de ligar para a supervisora. Primeiro quando eu ligo pra ela e explico "oi (nome da professora) assim, assim, aconteceu isso, eu fiquei pensando muito, eu fiquei chocada, ou isso tal", ela sempre me ajuda a refletir, ela me ajuda a enxergar melhor.

Fonte: Banco de Dados da Pesquisa: Entrevista - Bolsista 3 Pibid- Pedagogia.

Outra importante prática que faz parte das reuniões ritualizadas é a da leitura de textos. Como já inferimos, a leitura é prática importante para a ascese. A partir das leituras propostas o sujeito se aproxima dos discursos que serão tomados como verdadeiros. É principalmente a partir da leitura e da escuta de discursos verdadeiros, que serão constituídos os operadores da transformação do sujeito. A prática de escrever, ler e expor os discursos tomados como verdadeiros faz com que não estejam apenas guardados como memória em um diário de campo, mas "implantados na alma, 'nela arquivados', [...] e que assim façam parte de nós mesmos: em suma, que a alma os faça não somente seus, mas si mesmo" (FOUCAULT, 2004, p. 148).

Observemos dois exemplos. O primeiro é uma atividade de leitura reflexiva articulada às observações realizadas na escola, e o segundo, um relato de bolsista sobre o uso dos registros feitos no diário de campo em situação futura similar:

ATIVIDADE PROPOSTA COM LEITURA E USO DO DIÁRIO DE CAMPO: A partir do texto de Magda Soares (2004), os/as bolsistas deverão realizar uma escrita reflexiva sobre os conceitos de alfabetização e letramento, indicando as especificidades de cada processo e por que são considerados indissociáveis. A partir desta escrita, realizar observações nas turmas de alfabetização $\left(1^{\circ}, 2^{\circ}\right.$ e $3^{\circ}$ anos), buscando localizar e refletir sobre atividades específicas de alfabetização e letramento nas práticas cotidianas das professoras.

Fonte: Banco de Dados da Pesquisa: Trecho retirado do material de reunião do Pibid- Pedagogia. 
[...] sempre há discussão e debate sobre o que vivenciamos em salas de aula (pode ser alguns tópicos do que relatamos no diário). Sim, e muito. Procuro sempre fazer análises e opinar a respeito das observações feitas nas turmas. Isso é um material enriquecedor para os docentes. Às vezes são coisas boas e às vezes não, infelizmente. Creio que é uma forma de poder buscar soluções ou, até mesmo, respostas para perguntas e problemas frequentes. Ao escrever no diário de campo estou realizando algo importante, porque sempre que surgir algo parecido com o que já houve, busca-se nesse material para daí encontrar algo como solução e tentar inverter as coisas. O que julgo importante é ter tido uma oportunidade como essa de ter onde escrever/ relatar sobre nossas/minhas vivências em uma escola, em uma sala de aula.

Fonte: Banco de Dados da Pesquisa: Formulário- Bolsista 8 Pibid-Pedagogia.

O exercício de escrever no diário de campo faz com que a licencianda realize o movimento de olhar para o outro e olhar para si. Ao olhar para si, a partir dos discursos tomados como verdadeiros, a licencianda torna-se objeto de uma avaliação racionalizada que opera pela apropriação, unificação e subjetivação dessas verdades - dos discursos verdadeiros e do que delas pode ser transformado em princípios de ação e, em seguida, em ação. Esse conjunto de ações, ao repetir-se e fundamentar-se racional e argumentativamente nos rituais pibidianos, torna-se o próprio sujeito, o pibidiano.

Para Foucault (2004), a condução da conduta e a constituição de si estão implicadas na relação que o sujeito estabelece com as regras e valores que lhe são propostos; nas palavras do filósofo:

[...] designa-se, assim, a maneira pela qual eles se submetem mais ou menos completamente a um princípio de conduta, pela qual obedecem ou resistem a uma interdição ou a uma prescrição, pela qual respeitam ou negligenciam um conjunto de valores; o estudo desse aspecto da moral deve determinar de que modo, e com que margem de variação ou de transgressão, os indivíduos ou grupos se conduzem em referência a um sistema prescritivo, que é explícita ou implicitamente dado em sua cultura, e do qual eles têm consciência mais ou menos clara (FOUCAULT, 2004, p. 211). 
Dessa forma, as análises realizadas nos permitem afirmar que a proposta do Pibid se traduz num espaço rico de agenciamentos para o gerenciamento da conduta docente, entendendo agenciamento a partir de Rose (2011, p. 61) como "localização e conexão de rotinas, hábitos e técnicas dentro de domínios específicos de ação e valor".

A constituição de si, esse tornar-se professor/a, ocorre em meio ao que se aprendeu na licenciatura, ao que se observou e viveu nas práticas de iniciação à docência, ao que ficou guardado na memória sobre a docência e o ser professor/a, ser aluno, sobre a escola, desde aquilo que o sujeito tomou para si e o que refutou. Tudo isso permeia o processo de objetivação e que, em conflito com as problematizações realizadas a partir das propostas de reflexão das práticas observadas, possibilita a incorporação e/ou transformação de valores, operando na condução da conduta das licenciandas, constituindo suas subjetividades. O estudo sobre as técnicas de si possibilita-nos compreender os modos pelos quais se dá o processo de constituição do sujeito. Contudo, esse processo não ocorre de modo linear. Não é um processo mecânico nem se dá, pura e simplesmente, de forma igual para todos, pois implica os modos como cada um opera sobre si mesmo em seu contexto de ação.

É inegável, porém, a produtividade das técnicas de si no tocante à constituição de modos de ser do sujeito. É por meio de diferentes matrizes de experiência, matrizes de saber-poder-ética, que nos constituímos e somos constituídos ao longo da vida. Existe, portanto, um sujeito pibidiano, aquele que podemos ler nas práticas analisadas e nos discursos circulantes, aquele sujeito de uma formação docente enquanto matriz de experiência. Embora esses processos de constituição de si sejam extremamente produtivos para instituir modos de ser, conduzir a conduta, orientar e modular as escolhas de indivíduos que, passaram a fazer a experiência de si mesmos enquanto docentes, ao fim e ao cabo, não vamos encontrar sujeitos idênticos, mas aspectos comuns nos modos de conduzir-se, nos modos de ser docente.

A subjetivação se dá por meio de complexas redes onde se conectam verdades, modelos, poderes e forças, valores e princípios encontrados 
nos diferentes contextos culturais pelos quais passamos ao longo da vida. Portanto, os efeitos sob os nossos modos de ser, as subjetividades que nos formam e conformam são sempre provisórias, instáveis e contingentes. Ao defendermos o diário de campo como um potente instrumento para a formação de professores, reivindicamos uma formação alicerçada nos fios constitutivos do saber, do poder e da ética. Tal instrumento torna-se então, uma tecnologia humana produtiva de formas específicas e contingentes de subjetividades docentes.

\section{Referências}

DAL'IGNA, M. C.; FABRIS, Elí Henn Fabris. Práticas de iniciação à docência no Pibid/ Unisinos: processo em avaliação. In: VIII Congresso Internacional de Educação e III Congresso Internacional de Avaliação. Gramado/RS/Brasil: Fundação de Apoio da Universidade Federal do Rio Grande do Sul/UFRGS, 2013.

FABRIS, E. T. H. A Relação Universidade e Educação Básica na Produção da Docência Contemporânea. Edital Universal CNPq2012. Programa de Pós-Graduação em Educação Unisinos. (2013-2016).

FOUCAULT, M. Então é importante pensar? Michel Foucault (Entrevista). Trad. Wanderson Flor do Nascimento. In: FOUCAULT, M. Dits et écrits. Paris: Gallimard, 1994, v. IV, p. 178-182.

FOUCAULT, M. Ditos e escritos III: Estética: literatura e pintura, música e cinema. Organização de Manoel Barros da Motta. Trad. Inês Autran Dourado Barbosa. Rio de Janeiro: Forense Universitária, 2001.

FOUCAUlT, M. Ditos e Escritos V: Ética, Sexualidade, Política. Trad. de Elisa Monteiro e Inês Autran Dourado Barbosa. Rio de Janeiro, Forense Universitária, 2004.

FOUCAUlT, M. A Hermenêutica do Sujeito. São Paulo: Martins Fontes, 2010b. 
GARCIA, M. M. A.; FONSECA, M. S.; LEITE, V. C. Teoria e prática na formação de professores: a prática como tecnologia do eu docente. Educação em Revista, Belo Horizonte, v. 29, n. 3, p. 233-264, set. 2013.

LARROSA, Jorge. Tecnologias do Eu e educação. In: SILVA, Tomaz Tadeu (org.). O sujeito da educação: estudos foucaultianos. 5. ed. Petrópolis: Vozes, 1994.

LEWGOY, A.; ARRUDA, M. P. Novas tecnologias na prática profissional do professor universitário: a experiência do diário digital. Revista Texto e contextos: Coletâneas em Serviço Social, Porto Alegre: EDIPUCRS, n. 2, p. 115-130, 2004.

MASSCHELEIN, J.; SIMONS, M. A pedagogia, a democracia, a escola. Belo Horizonte: Autêntica, 2014.

NIETZSCHE, F. Humano, demasiadamente humano. 3 ed. Trad. de Rubens Rodrigues Torres Filho. São Paulo: Abril Cultural, 1983.

OLIVEIRA, S. de. Tornar-se professor/a: matriz de experiência e processos de subjetivação na iniciação à docência. 2015. Tese (Doutorado em Educação) Programa de Pós-Graduação em Educação, UNISINOS: São Leopoldo, 2015.

ROCHA, S. P. V. Em que ainda somos niilistas. Revista Tecnologias de Comunicação e Subjetividade. Ano 16, $1^{\circ}$ sem. 2009.

ROSE, N. Governando a alma: a formação do eu privado. In: SILVA, T. T. (org.). Inventando nossos selfs: Psicologia, poder e subjetividade. Petrópolis: Vozes, 2011.

SENNETT, R. Juntos. Os rituais, os prazeres e a política da cooperação. 2. ed. Rio de Janeiro: Record, 2013.

Recebido: 16/05/2016

Received: 05/16/2016

Aprovado: 13/04/2017

Approved: 04/13/2017 